\title{
Implementasi Akreditasi dalam Perspektif Guru dan Kepala Sekolah di Yogyakarta
}

\author{
Enung Hasanah ${ }^{1}$, Sukirman Sukirman $^{2}$, Cucu Afriliandhi ${ }^{3}$, Asnawi Wijayanto ${ }^{4}$ \\ 1,2,3,4 Manajemen Pendidikan, FKIP, Universitas Ahmad Dahlan \\ Email: enung.hasanah@mp.uad.ac.id
}

\begin{abstract}
Implementation of accreditation-based school quality assurance is one form of quality assurance carried out by the government comprehensively. Therefore all schools/madrasahs are required to reaccredit schools every five years. The accreditation results become a picture of the quality of schools in general that are easily read by the public. In this case, teachers and principals are the people who directly experience the implementation of the government's accreditation policy. This study aims to explore the implementation of accreditation-based school quality assurance in Yogyakarta according to the perceptions of teachers and principals. This research will use the survey method. Quantitative research samples were determined randomly, with a total of 410 respondents. Quantitative data collection techniques used questionnaires, which were distributed online from March to June 2021. Data analysis techniques were carried out using descriptive quantitative methods. The results showed that most teachers and principals had a positive perception of the implementation of school accreditation to ensure the quality of education in schools. This positive perception is one of the supporting factors for increasing public confidence in accreditation results to measure school quality in Indonesia.
\end{abstract}

Keywords: Accreditation, Teachers, Principals, School Quality Assurance

\begin{abstract}
Abstrak. Implementasi penjaminan mutu sekolah berbasis akreditasi merupakan salah satu bentuk penjaminan mutu yang dilakukan oleh pemerintah secara komprehensif, oleh sebab itu semua sekolah/madrasah wajib melakukan reakreditasi sekolah setiap lima tahun sekali. Hasil akreditasi menjadi gambaran kualitas sekolah secara umum yang dengan mudah dibaca oleh masyarakat. Dalam hal ini, guru dan kepala sekolah merupakan orang-orang yang secara langsung mengalami pelaksanaan kebijakan akreditasi dari pemerintah. Penelitian ini bertujuan untuk mengeksplorasi implementasi penjaminan mutu sekolah berbasis akreditasi di Yogyakarta menurut persepsi guru dan kepala sekolah. Penelitian ini akan menggunakan metode survei. Sampel penelitian kuantitatif ditentukan secara random dengan jumlah responden sebanyak 410 orang. Teknik pengumpulan data kuantitatif menggunakan kuesioner yang dibagikan secara online mulai bulan Maret-Juni 2021. Teknik analisis data dilakukan dengan metode kuantitatif deskriptif. Hasil penelitian menunjukan bahwa mayoritas para guru dan kepala sekolah memiliki persepsi positif tentang implementasi akreditasi sekolah sebagai salah satu cara untuk menjamin mutu pendidikan di sekolah. Persepsi positif ini merupakan salah satu factor pendukung untuk terjadinya peningkatan kepercayaan masyarakat terhadap hasil akreditasi sebagai basis ukuran mutu sekolah di Indonesia.
\end{abstract}

Kata Kunci: Akreditasi, Guru, Kepala Sekolah, Penjaminan Mutu Sekolah

\section{PENDAHULUAN}

Pertumbuhan ekonomi di negara mana pun, ditentukan oleh adanya perkembangan pengetahuan dan peningkatan kualitas sumberdaya manusianya. Oleh sebab itu, terbentuknya pendidikan berkualitas telah menjadi prioritas bagi bangsa mana pun (Ibrahim, 2014a). Di berbagai negara telah dikembangkan strategi-strategi pengembangan kualitas sumberdaya manusia, melalui peningkatan kualitas pendidikan (Lee \& Gunderson, 2018), yang di antaranya dilakukan melalui proses penjaminan mutu pendidikan.

Akreditasi sekolah merupakan salah satu cara yang dipandang efektif dalam upaya meningkatkan standar kualitas dalam pengajaran 
dan pembelajaran sesuai dengan standar yang ditetapkan (Diaz Segismundo, 2017). Dalam sistem pendidikan Indonesia, seluruh sekolah/madrasah yang berada dalam naungan kementrian pendidikan nasional maupun kementrian agama wajib mengikuti proses akreditasi sekolah/madrasah (Raharjo, 2013). Tujuan pelaksanaan akreditasi adalah untuk memberikan jaminan kepada masyarakat bahwa penyelenggaraan pendidikan di sekolah/madrasah berjalan sesuai dengan standar yang ditetapakan oleh pemerintah (Asopwan, 2018; SNP, 2011). Kemampuan Sekolah/Madrasah dalam memenuhi standar akreditasi menjadi tolok ukur pemerintah dalam memetakan kualitas Lembaga pendidikan di Indoensia (Setyaningsih, 2017), secara lebih komprehensif (Cenoz \& Gorter, 2011). Hasil akreditasi dianggap sangat penting karena dapat memberikan informasi yang lengkap mengenai kondisi kualitas proses pembelajaran maupun kualitas hasilnya (Hendarman, 2013)

Secara umum, sistem akreditasi sekolah memiliki peran yang sama seperti sistem penjaminan mutu lainnya (Can, 2016; Sallis, 2014), yaitu sebagai sebuah sistem kendali mutu pendidikan.

Akreditasi Sekolah/Madrasah diharapkan dapat memicu peningkatan produktivitas pendidikan (Hasanah, E., ; Purnawan, P.; Kuat, K., Hamidun, 2020; Istikomah \& Ayuwanti, 2017). Selain itu, akreditasi juga berfungsi untuk memastikan bahwa lulusan sekolah dapat disiapkan untuk menjadi lulusan yang memiliki daya adaptif dalam situasi teraktual (Ryan, 2011). Kemampuan siswa dalam mengembangkan kemampuan adaptif, baik sikap maupun keterampilan, diharapkan dapat membantu mempermudah para lulusan untuk dapat menghadapi berbagai tantangan kehidupan nyata ketika mereka kelak sudah lulus dan aktif di masyarakat. Oleh sebab itu, akreditasi sekolah hendaknya menjadi tanggung jawab semua pihak terkait di sekolah.

Guru dan kepala sekolah merupakan pihak yang secara langsung mengalami proses dan hasil akreditasi serta mengetahui bagaimana sikap masyarakat terhadap hasil akreditasi. Persepsi guru dan kepala sekolah mengenai implementasi akreditasi sekolah dapat memengaruhi keseriusan sekolah dalam membangun kultur penjaminan mutu sekolah, maka hal itu perlu diketahui untuk memudahkan para pengelola sekolah dalam melaksanakan pembinaan dan proses penjaminan mutu sekolah dengan cara yang baik dan berkelanjutan. Namun hingga saat ini penelitian mengenai persepsi para guru dan kepala sekolah mengenai implementasi akreditasi sekolah masih sangat jarang ditemukan. Oleh karena itu, studi ini bertujuan untuk mengeksplorasi pelaksanaan penjaminan mutu sekolah berbasis akreditasi di Indonesia berdasarkan sudut pandang para guru dan kepala sekolah. Tujuan penelitian ini adalah untuk mengeksplorasi pandangan para guru dan kepala sekolah tentang pelaksanaan akreditasi sekolah sebagai bagian dari proses penjaminan mutu pendidikan di Yogyakarta, yang dikenal sebagai kota pendidikan.

Penelitian

mengeksplorasi implementasi akreditasi sekolah/madrasah yang terjadi di Indonesia dari sudut pandang guru dan kepala sekolah. Untuk memandu jalannya penelitian maka penelitian ini beupaya untuk menjawab 3 pertanyaan berikut:

1. Bagaimana persepsi guru dan kepala sekolah tentang sekolah mengenai tingkat kesulitan tagihan bukti kinerja sekolah?

2. Bagaimana persepsi guru dan kepala sekolah tentang sekolah mengenai transparansi sistem akreditasi?

3. Bagaimana persepsi guru dan kepala sekolah tentang sekolah mengenai linieritas hasil akreditasi dengan minat masyarakat?

\section{METODE PENELITIAN}

Penelitian ini merupakan penelitian survei (Apuke, 2017) yang berupaya melakukan penelitian melalui penggalian data kuantitatif.

\section{Populasi dan sampel.}

Penelitian ini dilaksanakan di Yogyakarta, sehingga populasi dalam penelitian ini adalah semua guru pada semua jenjang yang ada di sekolah/madrasah di Yogyakarta. Berdasarkan hasil literasi terhadap tulisan Delice (Delİce, 2001), bahwa untuk mencapai reliabilitas data kuantitatif pada populasi besar yang tidak diketahui jumlahnya, minimal jumlah sampel sebanyak 250 responden. Maka jumlah 
sampel penelitian sebanyak 410 responden sudah memenuhi syarat keterwakilan populasi.

\section{Teknik pengumpulan data}

Teknik pengumpulan data yang dilakukan dalam penelitian ini yaitu melalui teknik pengambilan data kuantitatif yang dilakukan melalui penggalian data secara online (Paun, 2018), dengan cara menyebarkan instrument peneltian berupa google form kepada guru-guru negeri maupun swasta di Yogyakarta.

\section{Teknik analisis data}

Sebagaimana karakteristik kuantitatif, semua data yang dihasilkan dari kuisener diolah secara deskpritif kuantitatif dengan menggunakan bantuan aplikasi SPSS (Field, 2013). Data yang dihasilkan, dihitung tabel frekuensi tiap item pertanyaan untuk menemukan trend persepsi guru dan kepala sekolah mengenai implementasi akreditasi sekolah. Kemudian, untuk menentukan tingkatan intensitas jawaban setiap responden, kami mengelompokan setiap jawaban sesuai 5 skala likert yang digunakan dalam instrument penelitian. Dengan demikian, dapat ditemukan tingkatan respon dari kelompok jawaban untuk setiap butirnya.

\section{HASIL DAN PEMBAHASAN}

\section{Data responden}

Responden dalam penelitian ini adalah para guru dan kepala sekolah di Daerah Istimewa Yogyakarta, baik negeri maupun swasta, mulai dari tingkat SD, SMP, SMA, MA, dan SMK, yang mengisi angket secara sukarela. Oleh sebab itu proses penyebaran angket dilakukan secara acak ke group-group WA MGMP di Yogyakarta dan kepada peserta pelatihan penjaminan mutu sekolah yang diselenggarakan oleh Majelis Dikdasmen Pimpinan Wilayah Daerah Istimewa Yogyakarta pada tanggal 31 Mei 2021. Yogyakarta.

Dari angket yang telah disebarkan kepada para guru dan kepala sekolah mulai bulan Maret sampai Juni 2021, dihasilkan sebanyak 431 instrumen yang disi oleh para responden. Dari 431 intrumen yang diisi, hanya 410 partisipan yang mengisi angket secara lengkap, sehingga data yang dianalisis dalam penelitian ini sebanyak 410 angket, sehingga data yang diolah dalam penelitian ini hanya sebanyak 410 data responden.
Identitas responden dalam penelitian ini diidentifikasi dari sisi jenis kelamin, asal instansi, asal kabupaten, dan profesi. Secara detil, deskripsi data responden dalam penelitian ini dapat dilihat dalam tabel 1 berikut ini:

Table 1. Deskripsi data repsonden

\begin{tabular}{|l|l|r|r|r|r|}
\hline \multicolumn{7}{|c|}{ Gender } \\
\hline \multirow{2}{|c|}{} & Frequency & Percent & $\begin{array}{c}\text { Valid } \\
\text { Percent }\end{array}$ & $\begin{array}{c}\text { Cumulative } \\
\text { Percent }\end{array}$ \\
\hline Valid & L & 183 & 44.6 & 44.6 & 44.6 \\
\cline { 2 - 7 } & P & 227 & 55.4 & 55.4 & 100.0 \\
\cline { 2 - 7 } & Total & 410 & 100.0 & 100.0 & \\
\hline \multicolumn{7}{|c|}{ Asal Instansi } \\
\hline Valid & SD & 180 & 43.9 & 43.9 & 43.9 \\
\hline \multicolumn{7}{|c|}{ SMA } & 59 & 14.4 & 14.4 & 58.3 \\
\hline & SMK & 47 & 11.5 & 11.5 & 69.8 \\
\hline \multicolumn{7}{|c|}{ SMP } & 124 & 30.2 & 30.2 & 100.0 \\
\hline & Total & 410 & 100.0 & 100.0 & \\
\hline \multicolumn{7}{|c|}{ Profesi } \\
\hline Valid & kepala & 135 & 32.9 & 32.9 & 32.9 \\
& sekolah & & & & \\
\hline \multicolumn{7}{|c|}{ Guru } & 275 & 67.1 & 67.1 & 100.0 \\
\hline & Total & 410 & 100.0 & 100.0 & \\
\hline
\end{tabular}

\section{Hasil penelitian}

Pada bagian ini disajikan deskripsi data kuantitatif sekaligus data kualitatif mengenai persepsi guru dan kepala sekolah tentang tagihan-tagihan bukti kinerja dalam akreditasi, persepsi guru dan kepala sekolah tentang transparansi proses akreditasi serta persepsi guru dan kepala sekolah tentang linieritas hasil akreditasi sekolah dengan minat masyarakat. Data mengenai persepsi guru dan kepala sekolah mengenai implementasi akreditasi digali melalui penyebaran angket yang berisi pertanyaan dengan 5 skala likert. Secara detil data hasil penelitian ini sebagai berikut:

\section{a. Tingkat kemudahan tagihan-tagihan bukti kinerja dalam akreditasi dalam perspektif guru dan kepala sekolah}

Untuk menggali persepsi guru mengenai tagihan-tagihan bukti kinerja dilakukan dengan mengajukan pertanyaan sebagai berikut: tagihantagihan kinerja akreditasi mudah dan simple. Dari pertanyaan tersebut, terjaring data sebagaimana dicantumkan dalam table 2 berikut ini: 
Table 1. Tingkat kemudahan tagihan-tagihan bukti kinerja akreditasi

\begin{tabular}{|c|c|c|c|c|c|}
\hline & & Frequency & Percent & $\begin{array}{c}\text { Valid } \\
\text { Percent }\end{array}$ & $\begin{array}{l}\text { Cumulative } \\
\text { Percent }\end{array}$ \\
\hline \multirow[t]{6}{*}{ Valid } & $\begin{array}{l}\text { Sang } \\
\text { at } \\
\text { sulit }\end{array}$ & 23 & 5.6 & 5.6 & 5.6 \\
\hline & Sulit & 218 & 53.2 & 53.2 & 58.8 \\
\hline & $\begin{array}{l}\text { cuku } \\
\mathrm{p}\end{array}$ & 118 & 28.8 & 28.8 & 87.6 \\
\hline & $\begin{array}{l}\text { muda } \\
\mathrm{h}\end{array}$ & 48 & 11.7 & 11.7 & 99.3 \\
\hline & $\begin{array}{l}\text { Sang } \\
\text { at } \\
\text { muda } \\
\mathrm{h} \\
\end{array}$ & 3 & .7 & .7 & 100.0 \\
\hline & Total & 410 & 100.0 & 100.0 & \\
\hline
\end{tabular}

Tabel 1. Menunjukan bahwa para guru dan kepala sekolah di Yogyakarta memiliki persepsi bahwa tagihan-tagihan bukti kinerja akreditasi tidak mudah untuk dipenuhi. Hal ini ditunjukan dengan jawaban responden yang sebagian besar $(53,2 \%)$ menyatakan sulit dan $5,6 \%$ guru dan kepala sekolah menyatakan sangat sulit. Sebanyak $28,8 \%$ menyatakan cukup, $11,7 \%$ menyatakan mudah dan $0,7 \%$ menyatakan sangat mudah.

Hasil kuisener menunjukan sebagian besar $(53,2 \%)$ responden menilai bahwa pemenuhan bukti kinerja akreditasi sekolah termasuk sulit, dan 5,6\% guru dan kepala sekolah menyatakan sangat sulit. Sisanya menyatakan sedang bahkan ada juga yang menyatakan tidak sulit.

Pandangan para guru dan kepala sekolah yang Sebagian besar menilai bahwa tagihan bukti kinerja dalam akreditasi termasuk hal yang sulit untuk dipenuhi karena kinerja sekolah yang dinilai dalam sistem akreditasi sekolah berdasarkan IASP 2020 (Hasanah, 2021) dinilai berdasarkan performa sekolah. Performa yang dinilai adalah tentang bagaimana kualitas lulusan yang telah dihasilkan, kualitas guru sebagai pendidik di sekolah, kualitas proses pembelajaran yang dilaksanakan, serta kualitas kepemimpinan dan kemampuan manajemen sekolah. Semua itu harus mampu dibuktikan oleh sekolah sebagai sebuah output mutu sekolah berupa luaran pendidikan, bukan hanya dokumen (Hasanah, Purnawan, et al., 2020). Hal ini sejalan dengan Batasan mutu pendidikan yang dikemukakan oleh peneliti sebelumnya yaitu prinsip-prinsip sistem pendidikan baru yang terkait didasarkan pada pencapaian pembelajaran, penetapan tujuan kolektif, kolaborasi, dan nilai-nilai dan visi bersama, dengan proses kerja sekolah yang didasarkan pada kerja tim yang kuat, dan pada proses belajar-mengajar yang terkait dengan evaluasi (Sitthisomjin et al., 2020).

Dalam hal ini, sekolah perlu menggunakan strategi penjaminan mutu dengan menerima masukan dari guru, siswa, fasilitas, kurikulum dan kebijakan pendidikan yang berstandar tinggi (Fasasi, 2006), sehingga mutu pendidikan yang dihasilkan sesuai target dan dapat mendukung tercapainya tujuan pendidikan nasional. Manajemen sekolah harus memantau input dan memastikan pemrosesan yang tepat sehingga pengetahuan yang relevan dan memadai akan diperoleh. Oleh karena itu, harus ada input dan pemrosesan yang berkualitas dari semua sumber daya. Kondisi ini oleh para guru dan kepala sekolah bukanlah hal yang mudah dilakukan, tapi perlu energi yang besar untuk dapat mewujudkannya.

Jika melihat mayoritas jawaban dari para responden tentang tingkat kemudahan/tingkat kesulitan tagihan-tagihan bukti kinerja akreditas, terdapat dua hal yang menjadi perhatian dalam pelaksanaannya. Di satu sisi, akreditasi diyakini memiliki pengaruh terhadap peningkatan kualitas sekolah/madrasah. Di sisi lain, pelaksanaan akreditasi sekolah/madrasah cenderung menambah beban bekerja guru maupun kepala sekolah. Pertambahan beban kerja guru dan kepala sekolah, memiliki dampak langsung terhadap stress yang dialami guru maupun kepala sekolah (Collie et al., 2012; Ismail et al., 2019), juga dapat memengaruhi tingkat kepuasan kerja guru (Hasanah, Suyatno, et al., 2020).

Tingkat stress terhadap pekerjaan bagi karyawan yang memiliki kesadaran dan integrasi tinggi lebih rendah dibandingkan dengan tingkat stress karyawan yang tidak memiliki kesadaran dan integrasi. Studi ini memberikan dukungan untuk minat berkelanjutan dan penelitian tentgang tantangan dan hambatan stresor (Liu et al., 2013). Sejumlah pemicu stres terkait pekerjaan termasuk waktu sibuk dalam setahun, seperti periode penilaian, tekanan kegiatan ekstra kurikulum, hal-hal yang tidak terduga, mengikuti laju perubahan, dan perubahan dalam kepemimpinan sekolah. Tingkat stress guru dapat memengaruhi kesejahteraan siswa di sekolah, bahkan ketika para guru berusaha 
menyembunyikan yang terjadi pada diri mereka (Glazzard \& Rose, 2019). Eratnya hubungan antara beban kerja guru dan tingkat stress guru, menunjukan pentingnya perhatian terhadap pengelolaan stress guru dalam praktik penjaminan mutu sekolah berbasis akreditasi. Ini menjadi bagian dari tugas para pimpinan di sekolah (Ali \& Hasanah, 2021; Citra Resmi \& Hasanah, 2020).

\section{b. Transparansi proses akreditasi.}

Untuk menggali data pandangan guru dan kepala sekolah tentang transparansi implementasi akreditasi sekolah di Yogyakarta, peneliti menyampaikan satu pernyataan kepada para responden. Transparansi yang dimaksud dalam penelitian ini adalah kejelasan prosedur dan objektivitas dalam pelaksanaan seluruh proses akreditasi, mulai dari prosedur sampai pada objektivitas penilaian. Pernyataan tersebut sebagai berikut: pelaksanaan akreditasi transparan. Tanggapan responden tampak dalam table 2 berikut ini:

Table 2. Pelaksanaan akreditasi transparan

\begin{tabular}{|l|l|r|r|r|r|}
\hline \multicolumn{2}{|l|}{} & Frequency & Percent & $\begin{array}{c}\text { Valid } \\
\text { Percent }\end{array}$ & $\begin{array}{c}\text { Cumulative } \\
\text { Percent }\end{array}$ \\
\hline Valid & $\begin{array}{l}\text { sangat } \\
\text { setuju }\end{array}$ & 29 & 7.1 & 7.1 & 7.1 \\
\cline { 2 - 6 } & setuju & 206 & 50.2 & 50.2 & 57.3 \\
\cline { 2 - 6 } & $\begin{array}{l}\text { kurang } \\
\text { setuju }\end{array}$ & 122 & 29.8 & 29.8 & 87.1 \\
\cline { 2 - 6 } & $\begin{array}{l}\text { tidak } \\
\text { setuju }\end{array}$ & 51 & 12.4 & 12.4 & 99.5 \\
\cline { 2 - 6 } & $\begin{array}{l}\text { sangat } \\
\text { tidak } \\
\text { setuju }\end{array}$ & 2 & .5 & .5 & 100.0 \\
\cline { 2 - 6 } & Total & 410 & 100.0 & 100.0 & \\
\hline
\end{tabular}

Tabel 2. menunjukan bahwa para guru dan kepala sekolah di Yogyakarta memiliki persepsi bahwa sistem penilaian akreditasi dilaksanakan secara transparan. Hal ini ditunjukan dengan jawaban responden yang sebagian besar meyatakan setuju dan sangat setuju (7,1 persen sangat setuju dan 50,2 persen setuju). Sebanyak 29,8\% menyatakan tidak setuju, $12,4 \%$ menyatakan sangat tidak setuju dan $0,5 \%$ menyatakan sangat tidak setuju.

Hasil penelitian menunjukan bahwa mayoritas responden memiliki persepsi bahwa implementasi akreditasi sekolah yang dilaksanakan di Yogyakarta berjalan secara transparan. Hal itu dapat dilihat dari jawaban para partisipan yang menjawab setuju dan sangat setuju sebanyak 7,1 persen sangat setuju dan 50,2 persen setuju. Adanya pengakuan dari para guru dan kepala sekolah tentang trasnparansi pelaksanaan akreditasi di sekolah-sekolah yang berada di Yogyakarta, menunjukan sebuah fakta bahwa proses penjaminan mutu berbasis akreditasi diakui sebagai sesuatu yang objektif dan sesuai dengan apa yang semestinya terjadi.

Transparansi dalam pelaksanaan proses penjaminan mutu merupakan hal positif dalam membangun perilaku organisasi yang sehat (Weick, 2017). Perilaku organisasi yang sehat menjadi factor penting dalam sebuah proses penjaminan mutu (Fasasi, 2006).

Akreditasi adalah salah satu cara agar lembaga pendidikan tetap mengikuti standar. Dengan meningkatnya jumlah Lembaga pendidikan di negara ini dan permintaan akan pekerja terampil di pasar global, ada kebutuhan mendesak untuk lebih meningkatkan kualitas pendidikan (Conchada \& Tiongco, 2015), untuk itu seluruh proses penilaian dan penjaminan mutu pendidikan seyogyanya dilakukan secara objektif dan transparan.

Akreditasi merupakan salah satu pilar Infrastruktur mutu nasional, karena kompetensi lembaga dijamin kesesuainnya melalui akreditasi yang dilakukan oleh lembaga akreditasi (Rankin \& Welsh, 2013), yang disebut sebagai Badan Akreditasi Nasional Sekolah/Madrasah (BAN $\mathrm{S} / \mathrm{M})$.

Konsep penjaminan mutu dan peningkatan kualitas dalam pendidikan perlu dilakukan sebagai bagian dari suatu kegiatan kontinum dan menunjukkan kebutuhan keduanya sebagai proses yang berkelanjutan (Elassy, 2015). Tujuan proses akreditasi mencakup peningkatan kualitas pendidikan dan pelatihan profesional secara terus menerus untuk menjawab kebutuhan masyarakat yang berkembang dan memenuhi praktik profesional dalam pendidikan (Prabowo et al., 2017).

Pelaksanaan akkreditasi sebagai cara yang dilakukan oleh pemerintah dalam melakukan control kualitas pendidikan. Penjaminan kualitas dalam banyak kasus didorong oleh penilaian mandiri yang berkelanjutan dan dengan mencari beberapa bentuk validasi atau akreditasi internal atau terkadang eksternal. Akreditasi, dalam 
pendidikan, adalah proses di mana suatu asosiasi atau lembaga mengevaluasi suatu lembaga atau program studi pendidikan dan secara resmi mengakui bahwa lembaga atau program studi tersebut telah memenuhi dan memenuhi, atau melampaui, persyaratan dan kriteria atau standar mutu pendidikan tertentu yang telah ditetapkan sebelumnya (Ibrahim, 2014b). Setidaknya ada dua efek pelaksanaan akreditasi terhadap sekolah/madrasah yaitu, yang pertama adalah terjadi kemajuan etos administratif yang berupaya menciptakan cara-cara menunjukan kualitas pendidikan berbasis bukti. Yang kedua adalah tentang mentalitas terhadap instruksi. Penyajian penilaian kualitas pengajaran dibuat secara impresif, dan lebih mempertimbangkan kapasitas pertunjukan di dalam lembaga pendidikan, misalnya, melihat cara mendidik, mengamati proses mendidik dan mencari pendekatan untuk meningkatkannya (Makhoul, 2019). Penerapan jaminan kualitas dan akreditasi kualitas adalah rahasia di balik kesuksesan sebagian besar institusi pendidikan di seluruh dunia. Dengan demikian, pelaksanaan akreditasi sekolah merupakan upaya untuk menjamin agar kualitas pendidikan berjalan sebagaimana standar yang telah ditentukan.

\section{c. Persepsi guru dan kepala sekolah tentang linieritas hasil akreditasi sekolah dengan minat masyarakat.}

Persepsi guru dan kepala sekolah mengenai linieritas antara hasil akrediatsi dengan minat masyarakat digali dengan satu pernyataan positif, menggunakan 5 skala likert. Pernyataan tersebut adalah: nilai akreditasi sekolah linier dengan minat masyarakat. Tanggapan responden mengenai hal tersebut dapat dilihat dalam tabel 3 sebagai berikut:

Tabel 3. Nilai akreditasi sekolah yang tinggi dapat meningkatkan minat masyarakat untuk menyekolahkan anaknya di sekolah

\begin{tabular}{|l|l|r|r|r|r|}
\hline \multicolumn{2}{|c|}{} & Frequency & Percent & $\begin{array}{c}\text { Valid } \\
\text { Percent }\end{array}$ & $\begin{array}{c}\text { Cumulative } \\
\text { Percent }\end{array}$ \\
\hline Valid & $\begin{array}{l}\text { tidak } \\
\text { setuju }\end{array}$ & 1 & .2 & .2 & .2 \\
\cline { 2 - 6 } & $\begin{array}{l}\text { kuang } \\
\text { setuju }\end{array}$ & 33 & 8.0 & 8.0 & 8.3 \\
\cline { 2 - 6 } & setuju & 264 & 64.4 & 64.4 & 72.7 \\
\cline { 2 - 6 } & $\begin{array}{l}\text { sangat } \\
\text { setuju }\end{array}$ & 112 & 27.3 & 27.3 & 100.0 \\
\cline { 2 - 6 } & Total & 410 & 100.0 & 100.0 & \\
\hline
\end{tabular}

Tabel 3. menunjukan bahwa para guru dan kepala sekolah di Yogyakarta memiliki persepsi bahwa nilai akreditasi linier dengan minat masyarakat. Hal ini ditunjukan dengan jawaban responden yang sebagian besar meyatakan setuju dan sangat setuju (27,3 persen sangat setuju dan 64,4 persen setuju). Sebanyak $8,3 \%$ menyatakan tidak setuju, $0,2 \%$ menyatakan sangat tidak setuju.

Dilihat dari frekuensi jawaban para responden menunjukan bahwa mayoritas guru dan kepala sekolah setuju bahwa nilai akreditasi memiliki implikasi terhadap minat masyarakat dalam menyekolahkan anak-anak mereka di sekolah. Hal ini sejalan dengan hasil penelitian Kumar, dkk bahwa manfaat Akreditasi terlihat jelas dalam transfer kredit siswa dari satu lembaga terakreditasi ke lembaga lain, penerimaan kualifikasi gelar yang lebih tinggi untuk melanjutkan pendidikan lebih lanjut di seluruh dunia, membandingkan dengan lembaga lain dan penerapan praktik terbaik, perbaikan berkelanjutan dalam keseluruhan proses dan ketersediaan dana. Dampak pada dimensi ini saling terkait dan dapat mengakibatkan restrukturisasi fungsi akreditasi. Dampak Akreditasi terhadap kualitas dan keunggulan institusi pendidikan telah diakui secara global melalui hasil-hasilnya, berdasarkan proses yang telah ditetapkan yang ditinjau dan direvisi secara berkala oleh para profesional di bidang yang relevan, misalnya kurikulum/akademisi, proses belajar-mengajar dan penelitian, dan lain-lain. Dalam hal ini, para responden memiliki pandangan bahwa kualitas akreditasi memiliki hubungan linier denagn minat masyarakat. Sejalan dengan itu Reputasi akademis dipengaruhi oleh posisi di peringkat teratas sebuah Lembaga pendidikan (Kumar et al., 2020).

Terdapat berbagai fakta yang menunjukan bahwa akreditasi mengarahkan program pendidikan ke arah pembentukan proses pendidikan yang lebih baik (Blouin et al., 2018). Selain itu, sekolah yang berada di bawah tekanan untuk menerapkan perbaikan berkelanjutan dan proses penjaminan kualitas agar tetap kompetitif di pasar pendidikan yang mengglobal. Akreditasi sebagai tekanan eksternal yang telah mendorong peningkatan kualitas Lembaga agar dapat 
memenuhi kriteria akreditasi (Bryant, 2013). Akreditasi juga dapat berfungsi sebagai mekanisme panduan yang optimal yang menggabungkan kriteria evaluasi yang efektif untuk kualitas pembelajaran di lembaga pendidikan (Makhoul, 2019).Selain itu, nilai akreditasi menjadi salah satu faktor yang dapat menarik minat warga untuk memilih sekolah (Fira et al., 2020; Hanina Alifah \& Roesminingsih, 2018). Dengan demikian masuk akal jika nilai akreditasi memengaruhi minat masyarakat untuk menyekolahkan anakanaknya. Kesadaran masyarakat tentang makna nilai akreditasi tersebut disadari oleh para guru dan kepala sekolah sebagai sebuah fakta yang tidak terbantahkan di Yogyakarta, sehingga diharapkan hal tersebut dapat mendorong motivasi para guru dan kepala sekolah di Yogyakarta untuk senantiasa membangun mutu pendidikan berkelanjutan di sekolahnya masingmasing agar sekolah mereka tetap menjadi pilihan masyarakat.

\section{KESIMPULAN}

Hasil penelitian menunjukan bahwa mayoritas para guru dan kepala sekolah di Yogyakarta memiliki persepsi positif tentang akreditasi. Dalam persepsi par aguru dan kepala sekolah, baik proses maupun hasil implementasi akreditasi sekolah di Yogyakarta dilaksanakan secara objektif dan transparan, sehingga muncul kepercayaan masyarakat terhadap nilai akreditasi sekolah.

\section{DAFTAR PUSTAKA}

Ali, S., \& Hasanah, E. (2021). Kepemimpinan Kepala Sekolah dalam Menjamin Mutu Pendidikan Pada Masa Pandemi Covid19 di SMA Muhammadiyah 3 Yogyakarta. Jurnal Ilmiah Mandala Education, 7(1).

Apuke, O. D. (2017). Quantitative research methods: A synopsis approach. Kuwait Chapter of Arabian Journal of Business and Management Review, 6(11). https://doi.org/10.12816/0040336

Asopwan, D. (2018). Studi Tentang Akreditasi Dalam Meningkatkan Produktivitas Sekolah. Indonesian Journal of Education Management and

\section{Administration Review.}

Blouin, D., Tekian, A., Kamin, C., \& Harris, I. B. (2018). The impact of accreditation on medical schools' processes. Medical Education. https://doi.org/10.1111/medu.13461

Bryant, M. (2013). International Accreditations as Drivers of Business School Quality Improvement. Journal of Teaching in International Business. https://doi.org/10.1080/08975930.2013.8 60345

Can, E. (2016). Open and distance education acreditation standards scale: Validity and reliability studies. International Journal of Environmental and Science Education.

Cenoz, J., \& Gorter, D. (2011). A holistic approach to multilingual education: Introduction. Modern Language Journal. https://doi.org/10.1111/j.15404781.2011.01204.x

Citra Resmi, U. D., \& Hasanah, E. (2020). Best Practice Leadership of The Principal in Covid-19 Prevention Primary School at SD Muhammadiyah Purbayan. Randwick International of Education and Linguistics Science Journal. https://doi.org/10.47175/rielsj.v1i3.150

Collie, R. J., Shapka, J. D., \& Perry, N. E. (2012). School climate and social-emotional learning: Predicting teacher stress, job satisfaction, and teaching efficacy. Journal of Educational Psychology, 104(4). https://doi.org/10.1037/a0029356

Conchada, M. I. P., \& Tiongco, M. M. (2015). A Review of the Accreditation Sistem for Philippine Higher Education Institutions. In Philippine Institute for Development Studies (PIDS).

Delİce, A. (2001). The sampling issues in quantitative research. Educational Sciences: Theory \& Practices.

Diaz Segismundo, M. C. (2017). Measuring Accreditation Experience: Impact on the Quality of Education of Selected ASAS Member-Schools In Luzon and the NCR. International Journal of Education and Research.

Elassy, N. (2015). The concepts of quality, quality assurance and quality 
enhancement. Quality Assurance in Education, 23(3), 250-261. https://doi.org/10.1108/QAE-11-20120046

Fasasi, Y. A. (2006). Quality Asurance: A Practical Solution To Examination Malpractices In Nigerian Secondary Schools. International Journal of African and African American Studies, 5(2).

Field, A. (2013). Discovering statistics using IBM SPSS statistics. In Statistics.

Fira, F. L. A., Ulfatin, N., \& Benty, D. D. N. (2020). Strategi Pemasaran Jasa Pendidikan Dalam Menarik Minat Masyarakat Melalui Program Kelas Khusus. ... Dan Manajemen Pendidikan.

Glazzard, J., \& Rose, A. (2019). The impact of teacher well-being and mental health on pupil progress in primary schools. Journal of Public Mental Health. https://doi.org/10.1108/JPMH-02-20190023

Hanina Alifah, N., \& Roesminingsih, E. (2018). Pengaruh manajemen humas dan citra sekolah terhadap minat orang tua di sub rayon 34 surabaya. Inspirasi Manajemen Pendidikan.

Hasanah, E., ; Purnawan, P.; Kuat, K., Hamidun, E. (2020). Pelatihan penjaminan mutu sekolah berbasis akreditasi di SMK Muhammadiyah 2 Bantul. Prosiding Hasil Pengabdian Kepada Masyarkat, 799-806.

Hasanah, E. (2021). Best practice penjaminan mutu lulusan berbasis iasp 2020 di sekolah menengah kejuruan. JAMP: Jurnal Adminitrasi Dan Manajemen Pendidikan, 4(2), 178-186. http://journal2.um.ac.id/index.php/jamp/ article/view/20366/8157

Hasanah, E., Purnawan, P., Kuat, K., \& Hamidun, E. (2020). Pelatihan penjaminan mutu sekolah berbasis akreditasi di SMK Muhammadiyah 2 Bantul. Prosiding Hasil Pengabdian Kepada Masyarkat, 799-806.

Hasanah, E., Suyatno, S., Tugino, T., \& Ali, S. (2020). Work Satisfaction Level of Private School Teachers in Yogyakarta Indonesia. Randwick International of
Social Science Journal. https://doi.org/10.47175/rissj.v1i3.107

Hendarman, H. (2013). Pemanfaatan Hasil Akreditasi dan Kredibilitas Asesor Sekolah/Madrasah. Jurnal Pendidikan Dan Kebudayaan. https://doi.org/10.24832/jpnk.v19i4.308

Ibrahim, H. A.-H. (2014a). Quality Assurance and Accreditation in Education. Open Journal of Education. https://doi.org/10.12966/oje.06.06.2014

Ibrahim, H. A.-H. (2014b). Quality Assurance and Accreditation in Education. OJE, 2(2), 106-110.

Ismail, S. N., Abdullah, A. S., \& Abdullah, A. G. K. (2019). The effect of school leaders' authentic leadership on teachers' job stress in the Eastern part of peninsular Malaysia. International Journal of Instruction, 12(2). https://doi.org/10.29333/iji.2019.1225a

Istikomah, D., \& Ayuwanti, I. (2017). Improving The Quality Of School As A Solutions Of Education Problem. International Conference On Educational Research And Innovation (Iceri).

Kumar, P., Shukla, B., \& Passey, D. (2020). Impact of accreditation on quality and excellence of higher education institutions. Investigacion Operacional.

Lee, S. M., \& Gunderson, M. (2018). Human resource development. In The Evolution of Korean Industrial and Employment Relations. https://doi.org/10.4324/97813157162519

Liu, C., Liu, Y., Mills, M. J., \& Fan, J. (2013). Job stressors, job performance, job dedication, and the moderating effect of conscientiousness: A mixed-method approach. International Journal of Stress Management, 20(4), 336-363. https://doi.org/10.1037/a0034841

Makhoul, S. A. (2019). Higher education accreditation, quality assurance and their impact to teaching and learning enhancement. Journal of Economic and Administrative Sciences. https://doi.org/10.1108/jeas-08-20180092 
Paun, M. (2018). Data and Goliath: the hidden battles to collect your data and control your world. Law, Innovation and Technology. https://doi.org/10.1080/17579961.2018.1 451267

Prabowo, H., Farida, G., \& Vidayanti, D. (2017). Implementing the Quality Assurance Sistem in Indonesian Higher Education. Aktual'ni Problemy Ekonomiky = Actual Problems in Economics.

Raharjo, S. B. (2013). Evaluasi trend kualitas pendidikan di indonesia. Jurnal Penelitian Dan Evaluasi Pendidikan. https://doi.org/10.21831/pep.v16i2.1129

Rankin, B. W. J., \& Welsh, C. (2013). Accreditation. In Encyclopedia of Forensic Sciences: Second Edition. https://doi.org/10.1016/B978-0-12382165-2.00235-X

Ryan, T. (2011). Quality assurance in higher education: A review of literature. Higher Learning Research Communications. https://doi.org/10.18870/hlrc.v5i4.257

Sallis, E. (2014). Total quality management in education: Third edition. In Total Quality Management in Education: Third Edition. https://doi.org/10.4324/9780203417010

Setyaningsih, C. D. (2017). Status akreditasi dan kualitas sekolah di sekolah dasar negeri. Jurnal Manajemen Dan Supervisi Pendidikan. https://doi.org/10.17977/um025v1i22017 p138

Sitthisomjin, J., Somprach, K., \& Phuseeorn, S. (2020). The effects of innovation management on school performance of secondary schools in Thailand. Kasetsart Journal of Social Sciences, 41(1). https://doi.org/10.1016/j.kjss.2018.02.00 7

SNP. (2011). Standar Nasional Perpustakaan. Standar Nasional Perpustakaan.

Weick, K. E. (2017). Perspective Construction in Organizational Behavior. In Annual Review of Organizational Psychology and Organizational Behavior (Vol. 4). https://doi.org/10.1146/annurevorgpsych-032516-113043 